\title{
AN IN SITU FIELD-ION MICROSCOPE STUDY OF THE RECOVERY BEHAVIOR OF ION-IRRADIATED TUNGSTEN AND TUNGSTEN ALLOYS ${ }^{\dagger}$
}

\author{
K. L. WILSON and M. I. BASKES \\ Sandia Laboratories, Livermore, CA 94550 . U.S.A. \\ and \\ D. N. SEIDMAN \\ Cornell University, Bard Hall, Department of Materials Science and Engineering and \\ the Materials Science Center, Ithaca, NY 14853, U.S.A.
}

(Received 4 June 1979)

\begin{abstract}
Five grades of tungsten specimens with different purity levels (resistivity ratios $R$ of $5 \times 10^{4}$, $1.5 \times 10^{4}, 50,15$ and 5) were irradiated in situ with $30 \mathrm{keV} \mathrm{W} \mathrm{W}^{+}$ions to a dose of typically $5 \times 10^{12}$ ion $\mathrm{cm}^{-2}$ at $18 \mathrm{~K}$. Examination with a low-temperature field-ion microscope (FIM) showed the isochronal-annealing spectra of the specimens to result from a large self-interstitial atom (SIA) flux at $\sim 38 \mathrm{~K}$, followed by significant SIA flux from $\sim 50$ to $80 \mathrm{~K}$ and a small amount of additional recovery up to $120 \mathrm{~K}$. The spectra for these five different $R$ value specimens were essentially identical between 18 and $120 \mathrm{~K}$. High-purity $\mathrm{W}$ specimens $\left(R=5 \times 10^{4}\right)$ doped with $5 \times 10^{-5}$ to $1 \times 10^{-4}$ atom fraction carbon showed only a small reduction in the amount of recovery observed for the long-range migration peak at $38 \mathrm{~K}$. The isochronal recovery spectra for W-Re alloy specimens $\left(5 \times 10^{-3}\right.$ and $3 \times 10^{-2}$ atom fraction $\mathrm{Re}$ ) were radically different from the isochronal recovery spectra of pure $\mathrm{W}$ specimens. For both alloys the recovery of the Stage I long-range migration peak at $38 \mathrm{~K}$ was strongly suppressed; for the $3 \times 10^{-2}$ atom fraction alloy, all recovery from 18 to $120 \mathrm{~K}$ was virtually eliminated. This result indicated that during the long-range migration substage at $38 \mathrm{~K}$ tightly-bound, immobile SIA-Re complexes were formed that suppressed the SIA-SIA reaction. However, this effect was only observed at these high $R e$ atom concentrations. The lack of any significant differences for the annealing spectra of the five purity-levels of undoped tungsten and the appearance of impurity effects only in the extremely concentrated W alloys (i.e. $5 \times 10^{-3}$ to $3 \times 10^{-2}$ atom fraction Re) indicated that the early Stage II recovery $(45-120 \mathrm{~K})$ observed in the FIM isochronal-annealing spectra of self-ion irradiated high-purity $\mathrm{W}$ was intrinsic in nature. Recause of the highly inhomogeneous SIA distribution of the $\mathrm{W}^{+}$ion damage, the SIA-SIA interaction during Stage I long-range migration at $38 \mathrm{~K}$ appeared to be the dominant trapping mechanism. The early Stage II SIA recovery was therefore attributed to the migration or dissolution of these SIA clusters
\end{abstract}

Résumé Nous avons irradié in situ à $18 \mathrm{~K}$ avec des ions $\mathrm{W}^{+}$de $30 \mathrm{keV}$, pour une dose de l'ordre de $5 \times 10^{12}$ ion $\mathrm{cm}^{-2}$, cinq types d'échantillons de tungstène de diverses puretés (rapport de résistivité $R$ égal à $5 \times 10^{4}, 1,5 \times 10^{4}, 50,15$ et 5). La microscopie à émission d'ions (MEI) à basse température a montré que le spectre de revenu isochrone des échantillons provenait d'un grand flux d'auto-interstitiels (AAI) à $38 \mathrm{~K}$ environ, suivi d'un flux notable d'AAI entre $50 \mathrm{~K}$ environ et $80 \mathrm{~K}$ et d'une petite restauration additionnelle jusqu'à $120 \mathrm{~K}$. Les spectres étaient pratiquement identiques entre 18 et $120 \mathrm{~K}$ pour les échantillons présentant les cinq valeurs différentes de $R$. Les échantillons de tungstène de haute pureté $\left(R=5 \times 10^{4}\right)$ dopés par une fraction atomique de carbone de $5,10^{5}$ á $1 \times 10^{-4}$ ne présentaient qu'une légère réduction du taux de restauration observé pour le pic de migration à longue distance de $38 \mathrm{~K}$. Le spectre de restauration isochrone des alliages de tungstène et de rhénium (fraction atomique de Re égale respectivement à $5 \times 10^{-3}$ et $3 \times 10^{-2}$ ) différait totalement de celui des échantillons de tungstène pur. Le pic de migration à longue distance du stade I était pratiquement inexistant dans les deux alliages; dans le cas de lalliage de fraction atomique $3 \times 10^{-2}$, il n'y avait pratiquement plus de restauration entre 18 et $120 \mathrm{~K}$. Ces résultats montrent qu'il se formait au cours du sous-stade de migration à longue distance à $38 \mathrm{~K}$ des complexes immobiles et fortement liés entre AAI et $\mathrm{Re}$, qui supprimaient la réaction AAI-AAI. On n'observait cependant cet effet que pour les fortes concentrations de Re. L'absence de différences significatives entre les spectres de revenu des échantillons de tungstène non dopés de cinq degrés de pureté différents et l'apparition d'effets d'impuretés seulement dans les alliages très concentrés (fraction volumique de Re à gale à $5 \times 10^{-3}$ et $3 \times 10^{-2}$ ) montrent que le début de la restauration du stade II ( 45 a $120 \mathrm{~K}$ ), que lon observe dans le spectre de recuit isochrone du MEI pour du tungstène de haute pureté irradié par des ions de tungstène, est de naturc intrinsćque. Du fait de la forte hétérogénéité de la répartition des dommages dirradiation par les ions $\mathrm{W}^{+}$. l'interaction AAI-AAI au cours de la migration à longue distance à $38 \mathrm{~K}$ du stade I apparait comme le mécanisme prépondérant de piègeage. Nous attribuons donc le début de la restauration du stade II des AAI à la migration ou à la dissolution de ces amas dAAI.

I Research supported by the United States Department of Energy. Additional support was received from the National Science Foundation through the use of the technical facilities of the Materials Science Center at Cornell University. 
Zusammenfassung--Wolframproben mit fünf verschiedenen Reinheitsgraden (Widerstandsverhältnisse $R=5 \cdot 10^{4}, 1,5 \cdot 10^{4}, 50,15$ und 5) wurden bei $18 \mathrm{~K}$ unter Beobachtung mit $30 \mathrm{keV}-\mathrm{W}^{+}$-Ionen bis zu Dosen von typisch $5 \cdot 10^{12} \mathrm{~cm}^{-2}$ bestrahlt. Die Untersuchung mit einem TieftemperaturFeldionenmikroskop zeigte, daß die isochronen Erholungskurven der Proben herrühren von einem großen Eigenzwischengitteratomfluß (ZGA-Fluß) bei $\sim 38 \mathrm{~K}$, gefolgt von einem beträchtlichen ZGA-Fluß zwischen $\sim 50$ und $80 \mathrm{~K}$ und einem weiteren kleinen Erholungsbeitrag bis zu $120 \mathrm{~K}$. Die Kurven für die fünf im $R$-Wert verschiedenen Proben waren zwischen 18 und $120 \mathrm{~K}$ im wesentlichen gleich. Die im Maximum weitreichender Wanderung bei $38 \mathrm{~K}$ beobachtete Erholung war bei hochreinen Wolframproben $(R=$ $5 \cdot 10^{4}$ ), die mit $5 \cdot 10^{-5}$ bis $1 \cdot 10^{-4}$ Atombruchteilen Kohlenstoff dotiert waren, nur wenig verringert. Die isochronen Erholungskurven von Wolfram-Rheniumlegierungen $\left(5 \cdot 10^{-3}\right.$ und $3 \cdot 10^{-2}$ Atombruchteilc Re) waren grundverschieden von denjenigen der reinen Wolframproben. Bei beiden Legierungen war die Erholung des Stufe-I-Maximums weitreichender Wanderung bei $38 \mathrm{~K}$ weitgehend unterdrückt; bei der Legierung mit $3 \cdot 10^{-2}$ Atombruchteilen war die gesamte Erholung zwischen 18 und $120 \mathrm{~K}$ praktisch verschwunden. Dieses Ergebnis zeigt, daß während der weitreichenden Wanderungs-Unterstufe bei $38 \mathrm{~K}$ stark gebundene, unbewegliche ZGA-Re-Komplexe gebildet werden, die die ZGA-ZGA-Reaktionen unterbunden haben. Allerdings wurde dieser Effekt nur bei dieser hohen Re-Konzentration beobachtet. Das Fehlen jeglicher aussagekräftiger Unterschiede zwischen den Erholungskurven der fünf verschieden legierten Wolframproben und das Auftreten von Verunreinigungseffekten nur bei hochkonzentrierten Wolframlegierungen (d.h. bei $5 \cdot 10^{-3}$ bis $3 \cdot 10^{-2}$ Atombruchteilen Re) deuten darauf hin, daß die Erholung am Anfang von Stufe II ( 45 bis $120 \mathrm{~K}$ ), die im Feldionenmikroskop an mit Eigenionen bestrahlten Proben beobachtet wurde, intrinsischer Natur waren. Wegen der sehr inhomogenen Verteilung der ZGA durch die $\mathrm{W}^{+}$-Ionenschädigung schien die ZGA-ZGA-Wechselwirkung der dominierende Einfangmechanismus der Stufe I bei $38 \mathrm{~K}$ zu sein. Daher wurde die ZGA-Erholung zu Anfang von Stufe II der Wanderung oder Auflösung dieser ZGA-Anhäufungen zugeschrieben.

\section{INTRODUCTION}

The study of the recovery behavior of radiation damage in the refractory b.c.c. metals has received increasing attention over the past few years because of their potential importance in advanced energy systems. Of particular interest is the Stage II isochronal recovery of metals, which begins after the uncorrelated long-range migration of the self-interstitial atom (SIA) (typically at temperatures below $100 \mathrm{~K}$ ) and continues until the prominent Stage III recovery peak at $\sim 0.2$ of the absolute melting temperature [1]. The Stage II recovery has been attributed to both extrinsic and intrinsic mechanisms. The interaction of SIAs with solute impurity atoms, in Stage II, has been studied in a number of irradiated f.c.c. alloys [2-17] and b.c.c. alloys [18-22]. On the other hand, there is also evidence for intrinsic behavior in Stage II involving SIA cluster growth [23-26]. In addition, complex extended SIA configurations have been proposed $[27,28]$ for b.c.c. irradiated metals. The experimental research program reported in this paper was aimed at determining whether the Stage II isochronal recovery for $\mathrm{W}$ was an intrinsic (i.e. involving only SIA-SIA interactions) or extrinsic (i.e. involving impurity atoms) phenomenon.

Since Thompson's [29] pioneering recovery experiments on neutron-irradiated $W$ there have been a number of other experiments on the isochronalrecovery behavior of thermal or fast-neutron irradiated W (Burger et al. [22], Coltman et al. [30] and Takamura et al. [31]) employing electrical-resistivity measurements. In addition, there have been several experiments on the isochronal-recovery behavior of electron-irradiated W (Neeley et al. [32], Kunz [33], Kunz et al. [34], Dausinger and Schultz [35] and Maury et al. [36]) also employing electrical-resistivity measurements. Dausinger and Schultz [35] have assigned the $38 \mathrm{~K}$ recovery peak, discussed in this paper, to close-pair recovery, while Maury et al. [36] have attributed it to the correlated recombination of freely migrating SIAs. Recently there have been a number of experiments on the isochronal-recovery behavior of electron, neutron, and proton or deutronirradiated tungsten (DiCarlo et al. [37], Okuda and Mizubayashi [38, 39] and Townsend et al. [40]) employing internal-friction and dynamic-modulus measurements. In all of the above research on tungsten there has been the suggestion that impurity atoms may have played an exceedingly important role in the Stage II recovery. Thus, in the present work, the experimental emphasis was on the determination of the role, if any, played by impurity atoms on the isochronal-recovery behavior of ion-irradiated tungsten. Our experiment used the field-ion microscope (FIM) technique to observe Stage II recovery on an atomic scale.

The FIM technique [41] offers a unique atomistic view of the spatial arrangement and recovery behavior of point defects, introduced by radiation damage, in metals. When an FIM specimen is pulse fieldevaporated, the lattice is dissected on an atom-byatom basis: in this way the spatial arrangement of SIAs and vacancies in the primary state of radiation damage is directly determined [42]. Alternatively when a specimen is irradiated at a low temperature (e.g. $10 \mathrm{~K}$ ) and then warmed isochronally, the SIA flux to the free surface can be directly observed $[43,44]$. Prior FIM research on the isochronal recovery of selfion irradiated tungsten [45-48] demonstrated that the SIA flux consisted of a large recovery peak centered at $f 38 \mathrm{~K}$; this peak was followed by a significant amount of SIA recovery between 45 and $120 \mathrm{~K}$. This research on 20 or $30 \mathrm{keV} \mathrm{W} \mathrm{W}^{+}$ion-irradiated W 
demonstrated that the long-range migration of an SIA occurs below $50 \mathrm{~K}$; the SIA flux observed above this temperature was classified as Stage II recovery.

The FIM experiments consisted of irradiating with $30 \mathrm{keV} \mathrm{W}^{+}$ions, in situ, five different purity levels of pure tungsten and four different $\mathrm{W}$ alloys $[\mathrm{W}(\mathrm{C})$ and $\mathrm{W}(\mathrm{Re})]$ at an irradiation temperature, $T_{i}$, below the onset of long-range migration of the single SIA. Isochronal warming experiments to $120 \mathrm{~K}$ showed that all five different purity levels of $\mathrm{W}$ (resistivity ratio $=5$ to $5 \times 10^{4}$ ) had essentially the same basic recovery spectrum. Whereas the four $W(C)$ and $W(R e)$ alloys exhibited a reduction in the total amount of long-range recovery; this effect was particularly strong for the $\mathrm{W}-3 \times 10^{-2}$ atom fraction (at. fr.) $\mathrm{Re}$ alloy. The reduced recovery observed in the $W$ alloys is readily understood in terms of the formation of tightly bound SIA-impurity atom complexes. However, these effects were only observed at extremely high impurity-concentrations not found in the five different purity levels of the unalloycd $W$ that were studied. We therefore concluded that the SIA recovery observed by FIM between 45 and $120 \mathrm{~K}$ in pure $W$ was intrinsic in nature, and we attributed the recovery to the migration and/or dissolution of SIA clusters formed at $-38 \mathrm{~K}$ during the single SIA longrange migration process.

\section{EXPERIMENTAL DETAIL}

\subsection{Materials employed}

The following five different purity-levels of $W$ and four $\mathrm{W}$ alloys were investigated:

(1) four-pass zone-refined single crystals $\left(R=5 \times 10^{4}\right)$;

(2) one-pass zone-refined single crystals $\left(R=1.5 \times 10^{4}\right)$;

(3) Westinghouse polycrystalline wire annealed at $2400^{\circ} \mathrm{C}$ for $1 \mathrm{~h}$ in a vacuum system which was at $<1 \times 10^{-5}$ torr $(R=50)$;

(4) Materials Research Corporation (MRC) VP. grade wire $(R=15)$;

(5) Westinghouse polycrystalline wire in the asreceived state $(R=5)$;

(6) four-pass zone-refined single crystals doped with 50 appm carbon in solid solution;

(7) Westinghouse polycrystalline wire doped with carbon in solid solution;

t The SSMS technique is only good to within an order of magnitude unless reference standards are used for each specific element in question. Reference standards were not available for $W$ when the analyses of our specimens were performed. The SSMS measurements were performed in the Chemical Analytical Facility of the Cornell Materials Science Center.

$\$$ The value of $\rho_{273 \mathrm{~K}}$ has been taken to be equal to $4.95 \times 10^{-6} \Omega \mathrm{cm}[49]$.

$\$$ Carbon is an interstitial impurity atom in tungsten with an extremely small solid-solubility; the solubility of carbon in tungsten appears to be $\leqslant 5 \times 10^{-3}$ at. fr. at $2475^{\prime} \mathrm{C}[51]$
(8) a commercial W $5 \times 10^{-3}$ at.fr. Re alloy; and

(9) a commercial $\mathrm{W}-3 \times 10^{-2}$ at.fr. Re alloy.

The zone-refined single-crystals werc grown from both $\sim 1$ and $1.6 \mathrm{~mm}$ diameter rods of commercial purity tungsten.

Two standard physical measurements were employed to determine the purity of these specimens. The first technique employed was chemical analysis in the form of spark-source mass-spectrometry (SSMS). $\dagger$ This technique gave us the chemical composition of the metallic elements present in the specimen; however, SMSS did not distinguish between impurity atoms which were in solid solution and those which were in clusters or precipitates. Interstitial impurityatom concentrations were measured by standard quantitative analysis techniques (e.g., the inert gasfusion technique for carbon), but again there was no determination of the location of the impurity element.

The second measurement of specimen purity was the resistivity ratio $\left[R=\rho_{273 \mathrm{k}} / \rho_{4.2 \mathrm{~K}}\right]$. The value of $\rho_{4.2 \mathrm{~K}}$ is sensitive to the total impurity-atom concentration in solid solution. Unfortunately, $R$ also does not provide any information on which impurity atoms were in solid solution. The tabulated values [45] of the specific resistivities of impurity atoms in $\mathrm{W}$ indicated that a reasonable average value to use was $\simeq 1 \times 10^{-6} \Omega \mathrm{cm}\left({\text { at. } \%)^{-1}}\right.$, although Dausinger et $a l .[50]$ have employed a value as low as $0.2 \times 10^{-6} \Omega \mathrm{cm}(\text { at. } \%)^{-1}$ for Mo in W.

Tables 1 and 2 summarize the results of the chemical analyses and the $R$ data for the different specimens employed in this study. The value $R \cong 5 \times 10^{4}$ corresponds to $-10^{-6}$ at.fr. impurity atoms, while $R \cong 5$ corresponds to an impurity-atom concentration of $\leqslant 10^{-2}$ at.fr. based on $1 \times 10^{-6} \Omega \mathrm{cm}\left(\text { at. }_{0}^{\circ}\right)^{-1}$ as the average specific resistivity of an impurity atom. It is clear from a comparison of Tables 1 and 2 that the chemical analyses and $R$ data are not in agreement. This is indicative of the fact that the concentration of impurity atoms in solid solution must have been quite different from the total impurity-atom concentration in each specimen.

\subsection{Preparation of $\mathrm{W}(\mathrm{C})$ alloys}

Both four-pass zone-refined and Westinghouse annealed tungsten wire were doped with $C \$$ by a quenching technique similar to the one described by Krautz et al. [52]. The single-crystal $\mathrm{W}$ specimen, which was quenched, was first electropolished to a diameter of $0.2 \mathrm{~mm}$; next, it was suspended vertically in a vacuum chamber which was backfilled to a partial pressure of $1 \times 10^{-4}$ torr methane. The electrical and thermal contacts to the specimen were made by clamping the specimen at its top end and immersing the bottom end in a liquid ternary-eutectic of gallium, indium and tin which has a melting point of $10^{\circ} \mathrm{C}$ (United Mineral and Chemical Corp., alloy UG-1). The specimen was resistively heated to $1500 \mathrm{C}$ for a period of $4 \mathrm{~h}$ and then radiation quenched by terminating the current. An annealed Westinghouse 


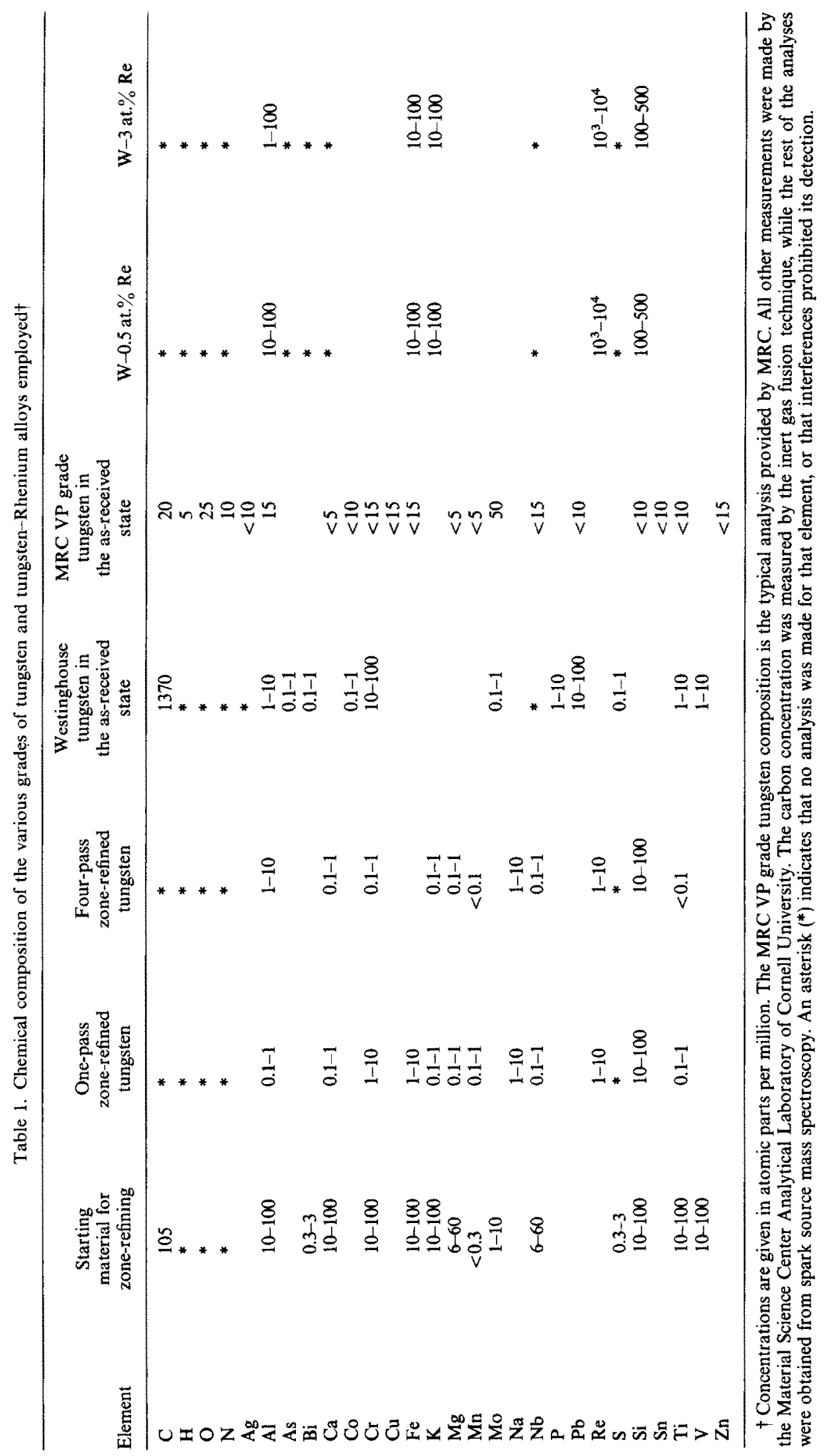




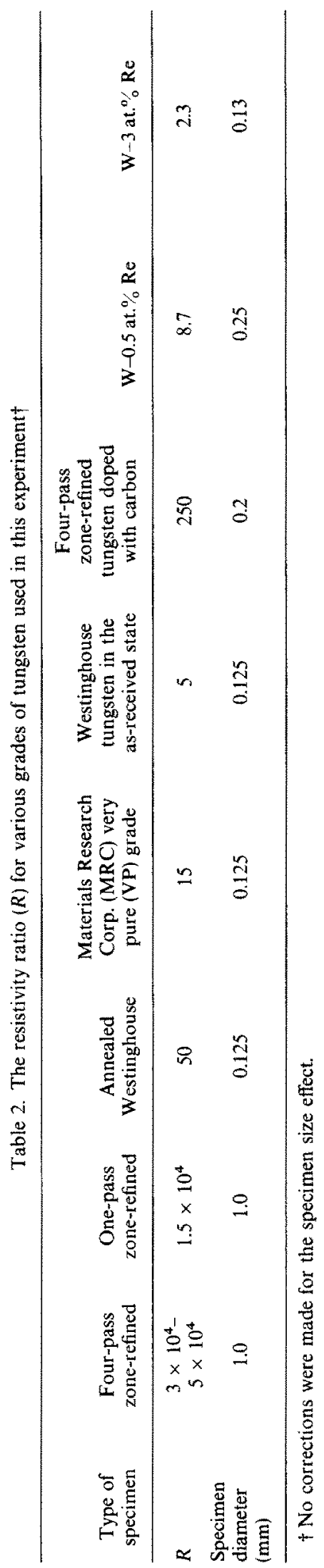




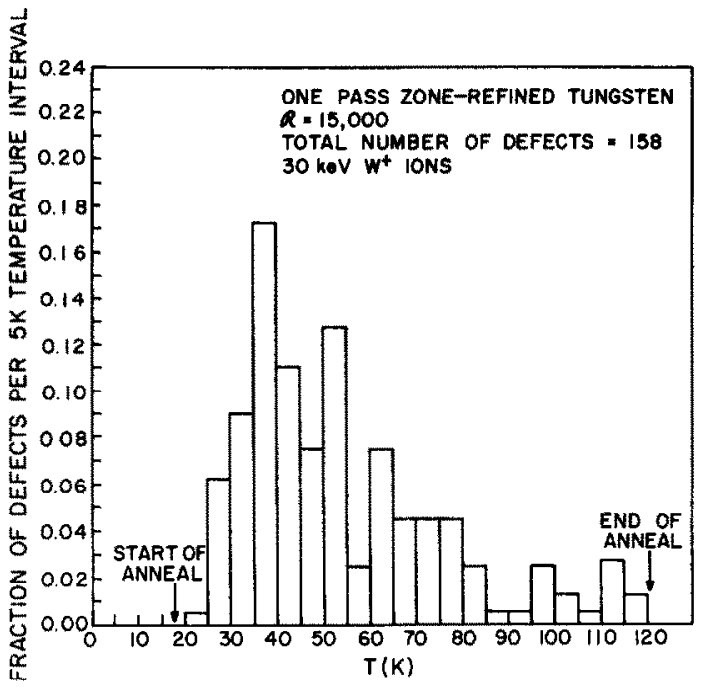

Fig. 1. A composite isochronal-annealing spectrum for one-pass zone-refined $W$ irradiated at $18 \mathrm{~K}$ with $30 \mathrm{keV}$ $\mathrm{W}^{+}$ions to a dose of $5 \times 10^{12}$ ion $\mathrm{cm}^{-2}$ and annealed to $120 \mathrm{~K}$ at a warming rate of $\sim 2.5 \mathrm{~K} \mathrm{~min}^{-1}$.

tungsten wire of $0.125 \mathrm{~mm}$ diameter was quenched in a similar manner after having been equilibrated for $4 \mathrm{~h}$ at $2000^{\circ} \mathrm{C}$ in $10^{-4}$ torr methane.

In the case of the four-pass zone-refined tungsten specimen the value of $R$ was $\cong 250$ after the quench. The only available value for the resistivity of a $C$ atom in solid solution in $\mathrm{W}$ is $3.85 \times 10^{-6}$ $\Omega \mathrm{cm}(\text { at. } \%)^{-1}[52]$; therefore, on the basis of this value the single crystal contained $\sim 50$ appm $C$. The $\mathrm{C}$ concentration in solid solution in the polycrystalline wire could not be quantitatively established. The wire was quenched from a higher temperature and at a faster quenching rate than was the single crystal; the grain boundaries in the wire specimen certainly allowed for the possibility of segregation of the rapidly diffusing carbon $\neq$ atoms. The end result was that the polycrystalline wire was extremely brittle after this C-doping treatment.

$\uparrow$ The quenching rate of a wire due to radiation cooling is inversely proportional to its diameter.

\$ The diffusivity of a $\mathrm{C}$ atom in a $\mathrm{W}$ lattice is given [53] by $\left(3.4 \times 10^{-3} \mathrm{~cm}^{2} \mathrm{~s}^{-1}\right) \exp (-1.6 \mathrm{eV} / \mathrm{kT})$.

$\$$ At $18 \mathrm{~K}$ there was no long-range migration of the SIA $[45,48]$. Recently we have repeated these experiments at $20 \mathrm{~K}$ employing $30 \mathrm{keV} \mathrm{W}{ }^{+}$ions and reconfirmed the fact that SIAs were not mobile at this temperature.

If The histograms exhibited in this section were constructed from the superposition of several runs; a maximum of three irradiations was performed on each tip. From 100 to $1000 \AA$ of metal was removed between each irradiation to increase the bluntness of the tip. In order to ascertain the effect of re-irradiating a given specimen two runs were made on the same crystal with only $5 \AA$ of metal removed between the two irradiations. No large changes were found in the isochronal-annealing spectra, indicating that the depleted-zone distribution and density did not play a major role in the observed recovery behavior. Table 3 summarizes the relevant data for all the isochronal anneals performed.

\subsection{The isochronal-recovery experiment}

The basic experimental FIM procedures have been described elsewhere [43-47]. Briefly, the specimens were electropolished, field evaporated to a useful tip radius $(200-400 \AA)$ and then irradiated with $30 \mathrm{keV}$ $\mathrm{W}^{+}$at $18 \mathrm{~K}$ in the FIM in the absence of the imaging gas or the electric field. $\S$ Typical fluences were $-5 \times 10^{12} \mathrm{~W}^{+} \mathrm{cm}^{-2}$. After each irradiation, the specimen was re-imaged and pulse field-evaporated; a minimum of $5 \AA$ of metal was removed by this technique. Then the temperature of the specimen was increased at a rate of $\sim 2.5 \mathrm{~K} \mathrm{~min}^{-1}$, while the FIM image was recorded on $35 \mathrm{~mm}$ ciné film at 0.5 frames $(s)^{-1}$. The arrival of SIAs at the surface was detected by the appearance of extra brightspots $[43-45,47,17]$. The flux of these extra brightspots was correlated with specimen temperature; thereby, producing an isochronal recovery spectrum for SIA recovery.

\section{RESULTS}

3.1 The isochronal-recovery behavior of the pure tungsten

The isochronal-recovery spectral| for the one-pass zone-refined $\left(R=1.5 \times 10^{3}\right)$, annealed Westinghouse $(R=50)$, the MRC VP-grade $(R=15)$, and the Westinghouse as-received W $(R=5)$, are presented in Figs $1-4$ respectively. The spectrum for the four-pass zone-refined $\left(R=5 \times 10^{4}\right)$ had been previously presented (see Fig. 2(a) of Ref. [47]). The histograms show the fraction of SIA defects per $5 \mathrm{~K}$ interval as a function of $T$ in the range $18-120 \mathrm{~K}$ for specimens that had been irradiated with $30 \mathrm{keV} \mathrm{W}^{+}$ions at $18 \mathrm{~K}$ in the absence of the imaging field. These four different grades (i.e. $R=5 \times 10^{4}-15$ ) of $W$ displayed re-

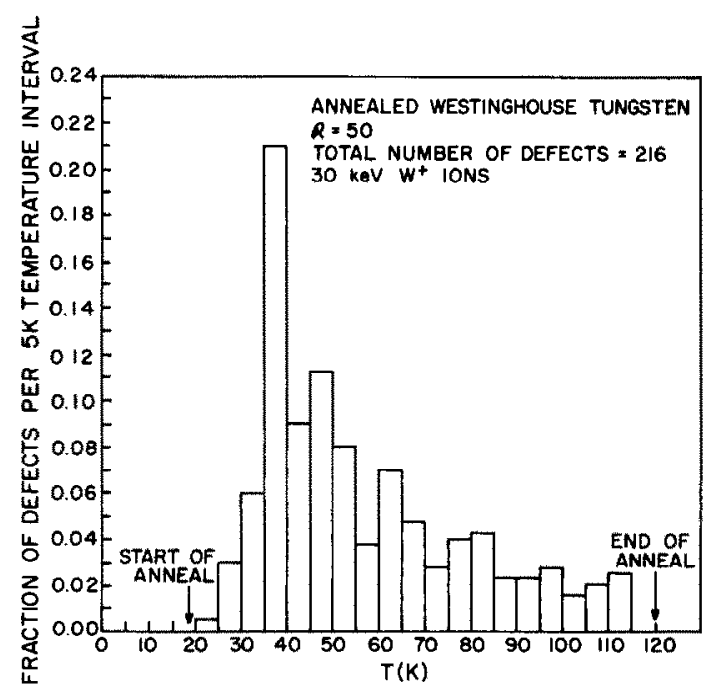

Fig. 2. A composite isochronal annealing spectrum for annealed Westinghouse $W$ irradiated at $18 \mathrm{~K}$ with $30 \mathrm{keV}$ $W^{+}$ions to a dose of $5 \times 10^{12}$ ion $\mathrm{cm}^{-2}$ and annealed to $120 \mathrm{~K}$ at a warming rate of $-2.5 \mathrm{~K} \mathrm{~min}^{-1}$. 


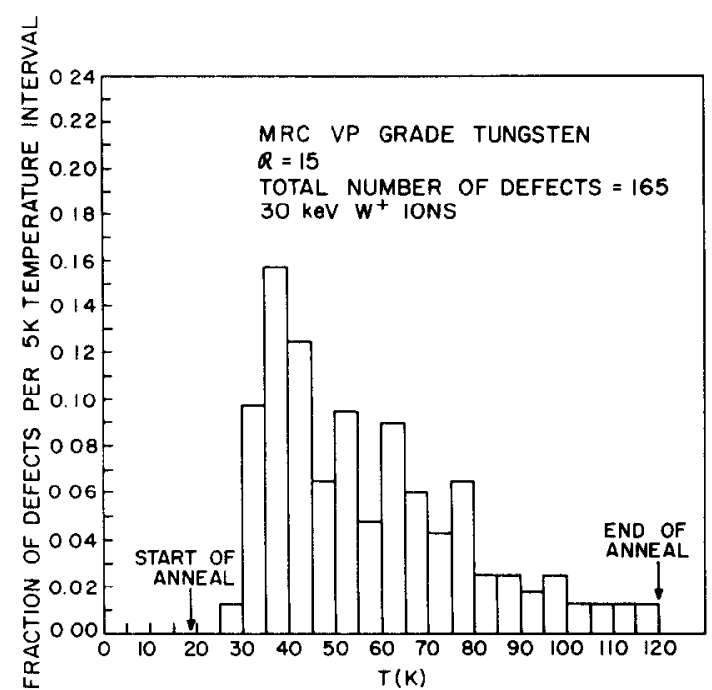

Fig. 3. A composite isochronal-annealing spectrum for MRC-VP grade $W$ irradiated in the as-received state at $18 \mathrm{~K}$ with $30 \mathrm{kcV} \mathrm{W}^{+}$ions to a dosc of $5 \times 10^{12}$ ion cm-2 and annealed to $120 \mathrm{~K}$ at a warming rate of $\sim 2.5 \mathrm{~K} \mathrm{~min}^{-1}$.

markably similar annealing spectra. The $38 \mathrm{~K}$ longrange migration peak was the dominant feature in all four cases. Three possible recovery peaks were found at $\sim 50,60$ and $80 \mathrm{~K}$ and an extremely ill-defined tail which might contain additional peaks at 95 and $110 \mathrm{~K}$ was also observed. The fifth grade of $\mathrm{W}$ studied was Westinghouse wire in the as-received unannealed state $(K=5)$. The isochronal spectrum (see Fig. 4) lacked the sharp peak structure found in the purer specimens but the dominant $38 \mathrm{~K}$ peak was still

† The above observations and comments are consistent with the lack of agreement between the $R$ values and the chemical analyses presented in Section 2.1 .

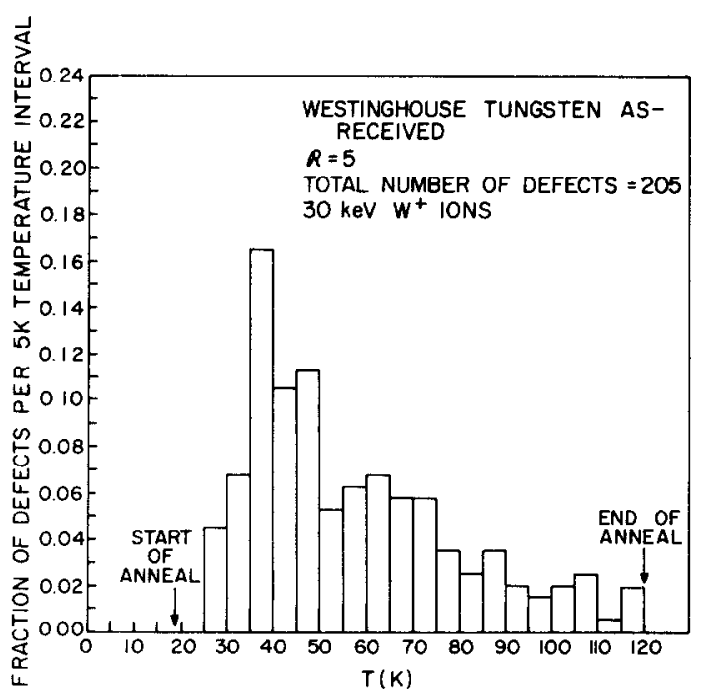

Fig. 4. A composite isochronal-annealing spectrum for Westinghouse $\mathrm{W}$ irradiated in the as-received state irradiated at $18 \mathrm{~K}$ with $30 \mathrm{keV} \mathrm{W}^{+}$ions and annealed to $120 \mathrm{~K}$ at a warming rate of $\sim 2.5 \mathrm{~K} \mathrm{~min}^{-1}$.

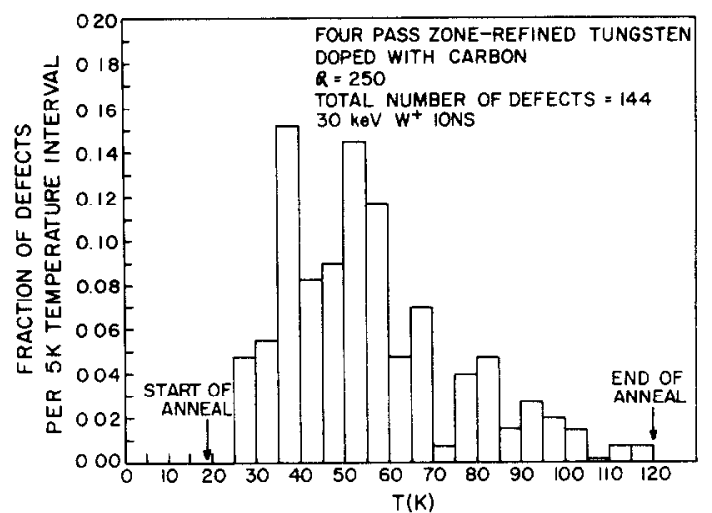

Fig. 5. A composite isochronal-annealing spectrum for four-pass zone-refined $\mathrm{W}$ doped with $\mathrm{C}$ and irradiated at $18 \mathrm{~K}^{-}$with $30 \mathrm{keV} \mathrm{W}^{+}$ions to a dose of $5 \times 10^{12}$ ion $\mathrm{cm}^{-2}$ and then warmed to $120 \mathrm{~K}$ at a rate of $\sim 2.5 \mathrm{~K} \mathrm{~min}^{-1}$.

present. Hence, the value of $R$ for pure $\mathrm{W}$ was varied by a factor of $10^{4}$ and yet the basic annealing spectrum had not shown any significant change.

The insensitivity of the observed recovery spectra to the value of $R$ was a somewhat surprising result. A possible explanation of this result is based on the following observations concerning the MRC-VP grade $\mathrm{W}$ : (1) the grain size or subgrain size has been found to be very small; i.e. many grain boundaries have been detected, by the FIM technique, in the unannealed MRC-VP grade $W$ specimens examined at Cornell; and (2) unpublished (A. Wagner, J. Amano and D. N. Seidman) atom-probe FIM studies, at Cornell, of unannealed MRC-VP grade $W$ revealed a total impurity-concentration of $\ll 10^{-4}$ at.fr. in the interior of the grains. Thus the $R$ value may have been determined by electron scattering from impurity atoms which had segregated to the subgrain boundaries or from the grain boundaries themselves. $\dagger$

\subsection{The isochronal-annealing spectra of $\mathrm{W}(\mathrm{C})$ alloys}

Figure 5 exhibits the isochronal annealing spectrum of the four-pass zone-refined $W$ with $\sim 5 \times 10^{-5}$ at.fr.

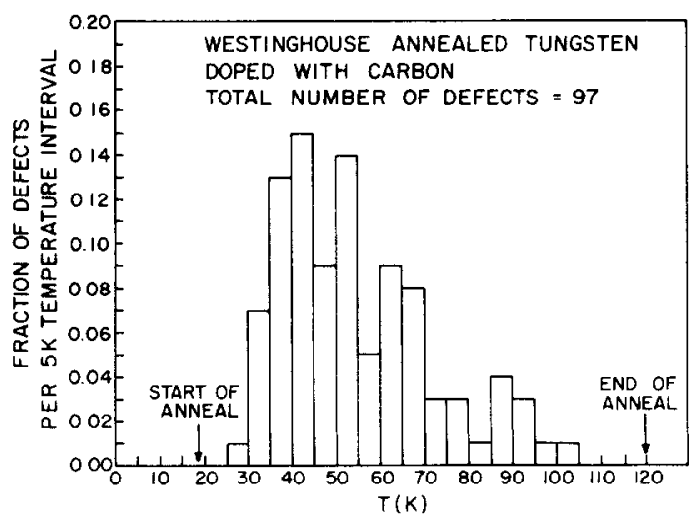

Fig. 6. A composite isochronal-annealing spectrum for Westinghouse $W$ doped with $C$ and irradiated at $18 \mathrm{~K}$ with $30 \mathrm{keV} \mathrm{W}^{+}$ions to a dose of $5 \times 10^{12}$ ion $\mathrm{cm}^{-2}$ and then warmed to $120 \mathrm{~K}$ at a rate of $\sim 2.5 \mathrm{~K} \mathrm{~min}^{-1}$. 


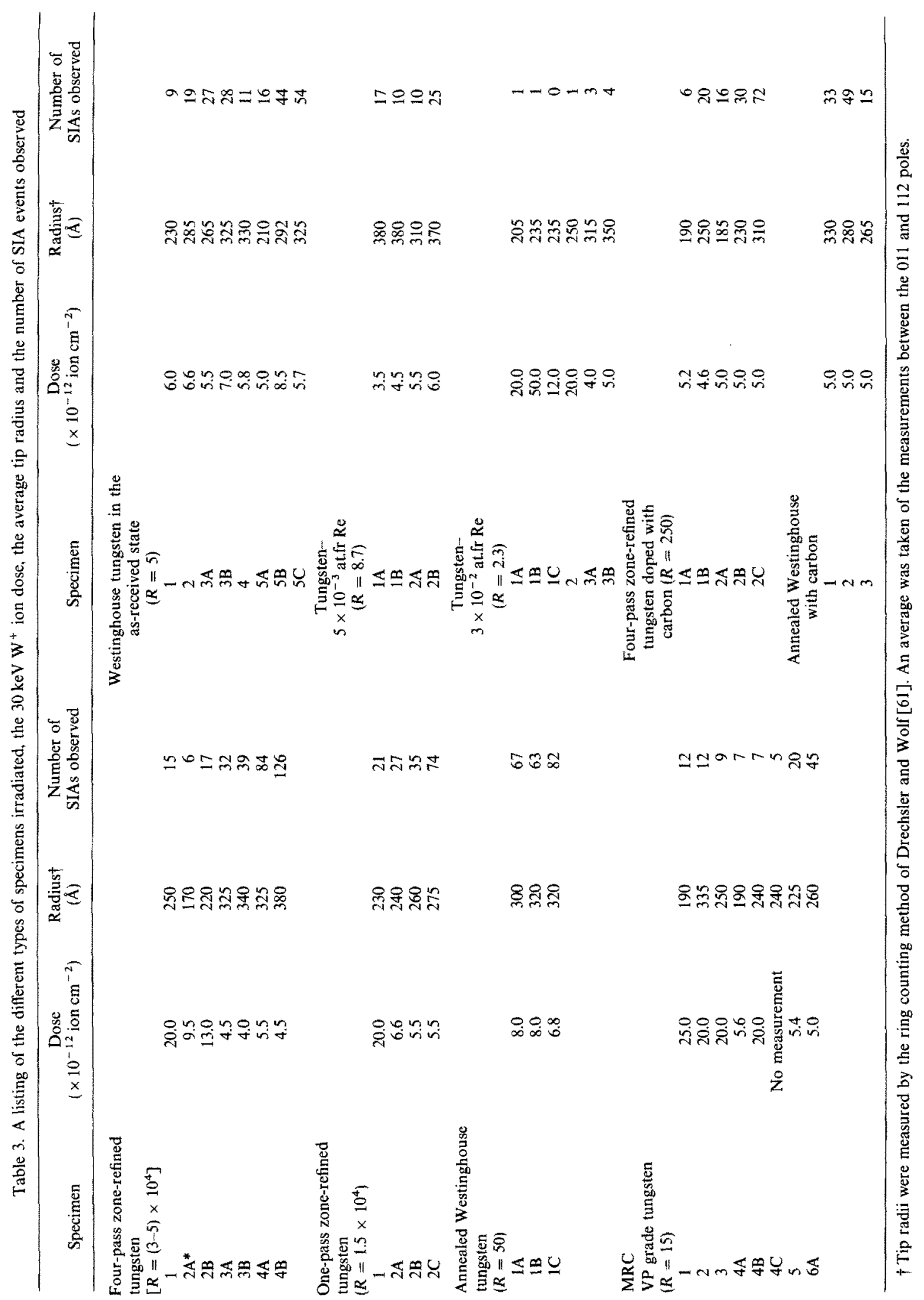




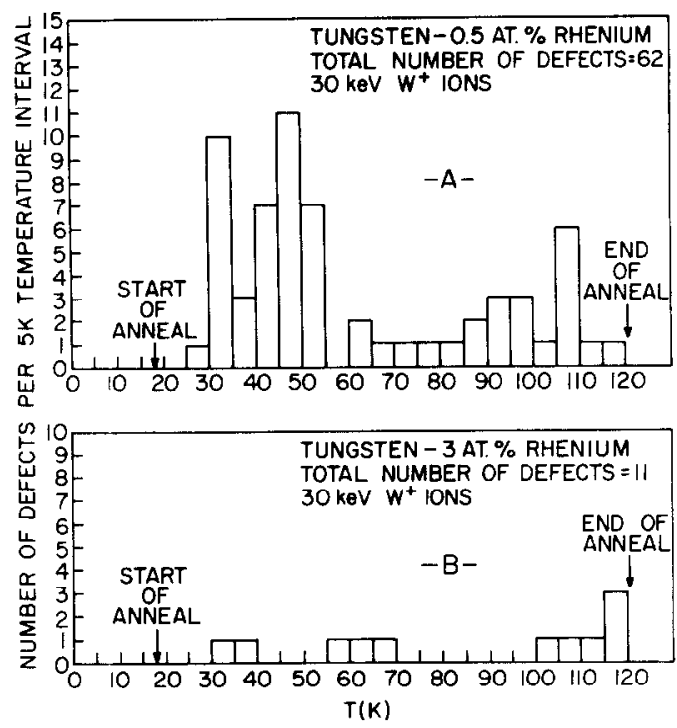

Fig. 7. (a) A composite isochronal-annealing spectrum for a W 0.5 at. $\% \operatorname{Re}$ alloy irradiated at $18 \mathrm{~K}$ with $30 \mathrm{keV} \mathrm{W}$ ions to a dose of $5 \times 10^{12}$ ion $\mathrm{cm}^{-2}$ and warmed to $120 \mathrm{~K}$ at a rate of $-2.5 \mathrm{~K} \mathrm{~min}^{-1}$. (b) A composite isochronalannealing spectrum for a $\mathrm{W}-3$ at. $\%$ Re alloy irradiated at $18 \mathrm{~K}$ with $30 \mathrm{keV} \mathrm{W}^{+}$ion $\mathrm{cm}^{-2}$ and warmed to $120 \mathrm{~K}^{2}$ at a rate of $-2.5 \mathrm{~K} \mathrm{~min}^{1}$.

$\mathrm{C}$ in solid solution. The Stage I long-range migration peak at $38 \mathrm{~K}$ had diminished only slightly in size. The isochronal annealing spectrum of the Westinghouse W doped with $C$ (Fig. 6) also showed only a small effect. Thus, while the $C$ level in solid solution in the four-pass zone-refined $\mathrm{W}\left(R \cong 5 \times 10^{4}\right)$ was increased by a factor of $\sim 200$ over its concentration in the undoped single crystals, the effect on the isochronal annealing spectrum was small. We stress that these high carbon concentrations are not found in the undoped $\mathrm{W}$ specimens.

\subsection{The isochronal-recovery behavior of $\mathrm{W}(\mathrm{Re})$ alloys}

The five grades of $W$ used for the studies presented in Section III each contained less than $10^{-5}$ at.fr. Re (see Table 1). The isochronal-annealing spectra of the irradiated $\mathrm{W}-0.5 \times 10^{-3}$ at.fr. $\operatorname{Re}\left(5 \times 10^{3} \mathrm{appm}\right)$ and W-3 $\times 10^{-2}$ at.fr. Re alloys are presented in Figs. 7(a) and (b). In Fig. 7 the ordinate is given as the number of SIAs per $5 \mathrm{~K}$ interval because of the small number of SIA events observed.

T This suppression of the SIA long-range migration recovery-peak has also been observed for a number of f.c.c. alloys (e.g. see Sosin and Neely [54]. Sosin [4], and Schilling et al. [55]).

* Calculated by assuming that the binding plus motion enthalpy (i.e. the dissociation enthalpy) is proportional to the peak temperature [4]: i.e. the dissociation enthalpy scales linearly with temperature $[4,17]$.

$\$$ This contrast pattern has also been referred to as an extra bright-spot by a number of authors, including the present ones.

A multiple-spot contrast pattern was considered as a single SIA event in the construction of the isochronalannealing histograms: hence, the use of the term defects in labeling the ordinates.
In the case of the $\mathrm{W}-5 \times 10^{-3}$ at.fr. Re alloy the long-range migration peak temperature was between 30 and $35 \mathrm{~K}$, instead of $35-40 \mathrm{~K}$, as in the case of the undoped $\mathrm{W}$ specimens. This shift is easily explained if one considers that only the SIAs close to the surface could have reached the surface without having been trapped by $\mathrm{Re}$ atoms. These SIAs would have constituted the early part of the flux because of the short diffusion distance to the surface. This downward shift in peak temperature with increasing impurity-atom concentration had been predicted by the Seidman and Lie treatment of this diffusion problem (see Fig. 6 in Ref. [43]). The substage II(a) peak at $50 \mathrm{~K}$ had now become the dominant peak, while recovery from 60 to $80 \mathrm{~K}$ had almost vanished. In addition, there was an increase in the amount of recovery above $90 \mathrm{~K}$.

The W-3 $\times 10^{-2}$ at.fr. Re alloy showed almost no recovery over the entire range from 18 to $120 \mathrm{~K}$. The recovery peak at $110 \mathrm{~K}$ was the largest one, but it contained only three SIAs after a total of six recovery experiments; therefore, for both of these alloys there is strong evidence that the SIAs formed SIA- $\mathrm{Re}$ atom complexes in Stage $I$. In the case of the W-3 $\times 10^{-2}$ at.fr. Re alloy the fraction of the Stage I SIAs trapped was appreciable since the $38 \mathrm{~K}$ peak was essentially eliminated, $\dagger$ as were all the Stage II peaks below $120 \mathrm{~K}$. The lack of a significant SIA flux below $120 \mathrm{~K}$ indicated that a SIA-Re atom complex has a dissociation enthalpy of $\geq 0.3 \mathrm{eV} \ddagger$ in the $\mathrm{W}-3 \times 10^{-2}$ at.fr. Re alloys. Further experimental work on this problem (Nielsen [56] and Nielsen and Seidman [57]) had indicated that the lower limit of the binding enthalpy of an SIA to a Re atom is $\sim 0.8 \mathrm{eV} . \$$ See Table 3 for a summary of all results on the irradiated specimens.

\subsection{SIA contrast patterns detected during isochronal anneals}

The primary SIA contrast pattern observed during the isochronal warming experiments was a single extra-atom spot. $\$$ Amongst the 1062 SIA events observed in the isochronal annealing experiments (see Section 4.1 ) $91.25^{\circ}$ oxhibited this simple contrast pattern; a double-spot contrast pattern was observed in $6.68^{\circ}$ of the total number of events; and the remaining $2.07^{\circ} \%$ of the SIA events were multiple-spot contrast patterns with three or more extra-atom spots. Figure 8 gives some examples of these contrast effects.

The single-spot contrast effect could have arisen from an atom on the surface (an adatom created by the total relaxation of an SIA at the surfacel or by a surface or a subsurface atom that was displaced upward as a result of an SIA lying several atomiclayers below the specimen's surface (Seidman and Lie [58]). The double-spot contrast pattern may have had two distinct origins. First, the contrast model of Seidman and Lie [58] predicted that for certain orientations the $\langle 110\rangle$ split SIA can produce a double-spot contrast effect at the surface: this model requires that 


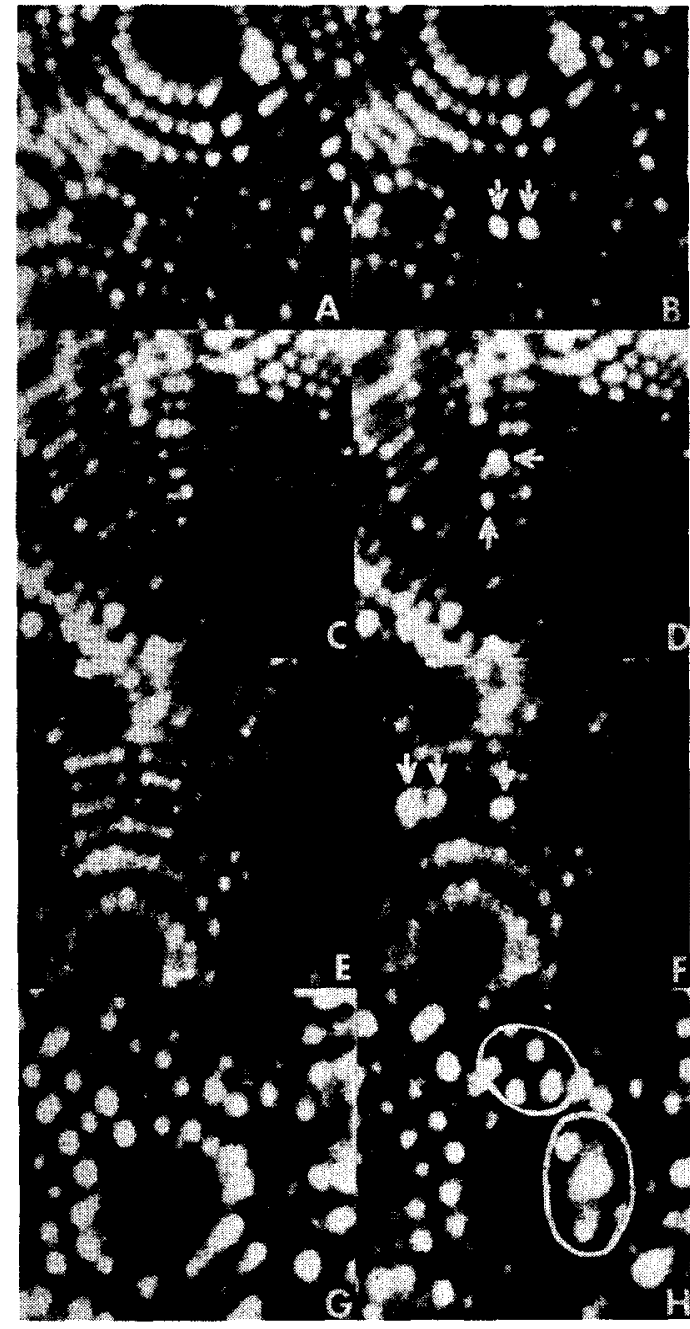

Fig. 8. (a) and (b) The appearance of a double-spot SIA contrast pattern detected in the $(110)$ terraces at $42.0 \mathrm{~K}$ during an isochronal anneal. (c) and (d) The appearance of another double-spot SIA contrast pattern in the (110) terraces at $54.0 \mathrm{~K}$ during an isochronal anneal. (e) and (f) The appearance of a multiple-spot SIA contrast pattern near the $(210)$ plane at $50.0 \mathrm{~K}$ during an isochronal anneal. (g) and (h) The appearance of a multiple-spot SIA contrast pattern near the (112) plane at $64.5 \mathrm{~K}$ during an isochronal anneal. The entire surface is seen to change dramatically in this region for this particular event. In all four cases the micrographs recorded before and after the appearance of the SIA were taken $2.0 \mathrm{~s}$ apart, which corresponds to a temperature interval of $\sim 0.08 \mathrm{~K}$

the SIA retains its identity as a subsurface defect. Second, the double-spot contrast pattern could indicate the arrival of a di-SIA complex at the surface. Analysis of the double-spot contrast patterns in all of

$\dagger$ Flashing is a common mode of tip failure whereby a shell of material is expelled from the surface. The tip can still be imaged at a higher voltage, but the SIAs have most likely been swept out of the tip volumc: scc Wilkes et al. [59] and Loberg [60] for more details on tip failure.

\pm This number was calculated for $30 \mathrm{keV} \mathrm{W}^{+}$ions for a dose of $5 \times 10^{12}$ ion $\mathrm{cm}^{-2}$ assuming approximately one observable SIA per incident ion: this number was borne out by our experimental results. the unalloyed $W$ specimens showed that the doublespot contrast effects occurred over the entire temperature range in which single-spot contrast effects were observed. The coexistence of single and double-spot contrast effects in the $38 \mathrm{~K}$ long-range migration peak indicated that both contrast effects had the same origin: that is, the single SIA. Therefore, a reasonable conclusion is that at least some of the SIA contrast effects were caused by the strain field of a subsurface SIA. Whether this mechanism was the only one that was operative cannot be ascertained at present.

Contrast patterns with three or more spots (see the pairs of FIM micrographs (e) and (f), and (g) and (h) in Fig. 8) were much larger in extent than the predicted strain field contrast effect patterns of Seidman and Lie [58] for the single SIA. While these events were only a small portion ( $\sim 2 \%$ ) of the total number of defects detected their appearance indicated that some form of SIA clustering must have occurred within the FIM specimen during the isochronal anneals. Because of the small number of multiple contrast patterns it was not clear if their migration enthalpy was possibly lowered by a large negative $p \Delta v_{i c}^{m}$ effect; where $\Delta v_{i c}^{m}$ is the volume change of migration of the SIA cluster and $p$ is the hydrostatic pressure due to the applied electric imaging field. With respect to the latter point the $100 \mathrm{~K}$ irradiation experiment of Scanlan et al. [45] and the $50 \mathrm{~K}$ irradiations by Wilson and Seidman [47] showed that the single-spot peak structure observed below $100 \mathrm{~K}$ in the isochronal anneals was not assisted by the electric field: their experiment do not rule out a $p \Delta v_{i c}^{m}$ effect for the SIA clusters. In fact, the three SIA events detected in the isochronal recovery below $T_{i}=100 \mathrm{~K}$ in the Scanlan et al. [45] experiment were multiplespot contrast effects.

\subsection{Control experiments}

Six control-runs were performed during the course of the isochronal annealing experiments. Three of the specimens were simply annealed from 18 to $120 \mathrm{~K}$ without being irradiated, while the other three specimens had been irradiated, but had flashed $t$ during the post-irradiation peel prior to the isochronal anneal.

One contrast pattern similar to an SIA was observed in the first control-run on an unirradiated specimen; no SIA contrast effects were observed in any of the subsequent control runs. This single contrast effect in these controls may have been caused by a gas impurity atom that had been adsorbed on the surface. The high electric field required for field ionization of helium kept impurity adsorption to a minimum [41d]. In one of the control runs, the specimen was exposed to the ion accelerator (at $\sim 10^{-5}$ torr argon gauge pressure) without the differential pumping system for $\sim 30 \mathrm{~min}$. No SIA contrast effects were observed in the subsequent control anneal from 18 to $120 \mathrm{~K}$. If the six control-specimens had been irradiated at $18 \mathrm{~K}$ and annealed in the standard way there would have been $\sim 150$ SIA events detected. $\ddagger$ 
Therefore an upper maximum to the gas impurity contamination effect was $\$ 0.7 \%$ for the isochronal anneals. This background was insignificant with respect to the SIA flux observed in the isochronal anneals reported in this paper.

\section{MAJOR EXPERIMENTAL RESULTS AND DISCUSSION}

The major experimental results are summarized as follows:

(1) The low-temperature isochronal-annealing spectrum of pure W $\left(R=5 \times 10^{4}\right)$, irradiated in situ with $30 \mathrm{keV} \mathrm{W} \mathrm{W}^{+}$ions to a typical fluence of $\sim 5 \times 10^{12} \mathrm{~cm}^{-2}$ at $18 \mathrm{~K}$ was shown to consist of a series of distinct recovery peaks at $\sim 38,50,65$ and $80 \mathrm{~K}$ with a small amount of additional recovery observed up to $120 \mathrm{~K}$. We had previously identified the $38 \mathrm{~K}$ peak as an SIA long-range migration substage. The remaining peaks were classified as substages of Stage II; therefore, Stage II of irradiated W begins at $45 \mathrm{~K}$ and not at $\sim 100 \mathrm{~K}$ as had been suggested by earlier investigators (see Ref. [44] for a discussion of this point).

(2) The isochronal annealing-spectrum of pure $\mathrm{W}$ observed by FIM between 18 and $120 \mathrm{~K}$ was insensitive to $R$ for values between $5 \times 10^{4}$ and 5 .

(3) Self-ion irradiated $\mathrm{W}$ doped with $\sim 5 \times 10^{-5}$ to $1 \times 10^{-4}$ at.fr. interstitial carbon, in solid solution, showed only a small reduction in the amount of recovery observed for the long-range migration peak at $38 \mathrm{~K}$ in undoped W. However, SIA-carbon atom interactions cannot be invoked in the explanation of early Stage II recovery in the high-purity $\mathrm{W}$, since $R \cong 5 \times 10^{4}$ corresponds to $\leqslant 2 \times 10^{-7}$ at.fr. $\mathrm{C}$ in solid solution.

(4) The isochronal-annealing spectra for self-ion irradiated $\mathrm{W}-5 \times 10^{-3}$ and $3 \times 10^{-2}$ at.fr. Re alloys were radically different from the isochronal-recovery spectra of pure tungsten. For both $\mathrm{W}(\mathrm{Re})$ alloys the amount of recovery for the long-range migration peak at $\sim 38 \mathrm{~K}$ was suppressed and in the case of the W-3 $\times 10^{-2}$ at.fr. Re alloy all recovery between 18 and $120 \mathrm{~K}$ was almost completely eliminated. This result constitutes strong evidence for the formation of immobile tightly-bound SIA-Re complexes during the long-range migration substage at $38 \mathrm{~K}$. However,

$\dagger$ We have found no evidence to support Okuda and Mizubayashi's $[38,39] \cdot$ conclusion that the recovery at $30 \mathrm{~K}$ in neutron-irradiated $\mathrm{W}$ was a result of the detrapping of SIAs from impurity atoms. It is noted that there is also a very fundamental disagreement between Townsend et al. [40] and Okuda and Mizubayashi [38, 39] on the interpretation of the $30 \mathrm{~K}$ internal-friction peak.

$\ddagger$ An SIA will make $<10^{4}$ jumps before it reaches the external surface of the FIM specimen, while the number of jumps for an SIA to reach a vacancy, in an isochronal anneal of an electron-irradiated specimen, is inversely proportional to the vacancy concentration and therefore is usually $>10^{4}$. these effects only became apparent at high Re concentrations. We stress again that in the high purity $W$ $\left(R \cong 5 \times 10^{4}\right)$, the Re impurity concentration in solid solution was $\leqslant 10^{-5}$ at.fr.

(5) The SIA contrast patterns detected in the isochronal anneals consisted primarily of single extraspots. However, the small number of large multiplespots indicated that some form of SIA clustering must have occurred below $120 \mathrm{~K}$ in Stage II during the isochronal-annealing experiments.

The lack of any significant change in the recovery spectrum for samples with $R=5 \times 10^{4}$ to $R=5$, lead us to the conclusion that for the unalloyed W specimens the SIA-impurity interactions did not make any appreciable contribution to the Stage II SIA flux. $\dagger$ Instead, we propose that SIA-SIA interactions dominated the recovery behavior. This situation resulted from the inhomogeneous distribution of SIAs created by the $30 \mathrm{keV} \mathrm{W}^{+}$ions in the FIM specimen. Each heavy metal-ion produced a depleted zone which consisted of a cloud of SIAs surrounding the vacancy-rich core $[42,43]$. Experiments performed by Beavan et al. [61] have shown that at an irradiation temperature of $18 \mathrm{~K} \mathrm{a} 20 \mathrm{keV} \mathrm{W}^{+}$ion in $\mathrm{W}$ can create a depleted zone consisting of $\sim 160$ vacancies surrounded by a significant number of SIAs within a $\sim 100 \AA$ radius. The SIA concentration within this cloud was as high as $\sim 10^{-2}$ at.fr. and the average impurity-atom concentration in the $5 \times 10^{4}$ samples was $\leqslant 10^{-6}$ at.fr.; therefore, the probability of an SIASIA interaction was several orders of magnitude greater than an SIA-impurity interaction. Recent experiments by Wei and Seidman [62] on W irradiated. at $10 \mathrm{~K}$, with $30 \mathrm{keV} \mathrm{W}^{+}, \mathrm{Mo}^{+}$or $\mathrm{Cr}^{+}$ions have substantiated the physical picture detailed above.

In the case of the $R=15$ specimens the impurityatom concentration in the interior of the subgrains was $\ll 10^{-4}$ at.fr. (see Section 3.1) so that the migrating SIAs sampled a lattice which was considerably purer than a first-order interpretation of the $R$ value would have lead us to believe. Furthermore it is also possible that the specific impurity atoms present in the impure tungsten do not form SIA-impurity atom complexes with the correct binding enthalpy to perturb the basic recovery spectrum. Once again, SIASIA interactions were more probable than SIAimpurity interactions.

These results should be contrasted with resistivity measurements on electron-irradiated metals: e.g. see Ref. [4-9] and [32-36]. In the case of electron-irradiated specimens the SIAs were distributed uniformly and at a low concentration relative to the concentration in the SIA cloud of the self-ion irradiated specimens. In addition, the mobile SIAs sampled many more lattice sites via random walk in the bulk electron-irradiated specimens than in the self-ion irradiated FIM specimen, because of the different SIA sink distribution. $\ddagger$ Therefore, SIA-impurity interactions were prominent at a much lower impurity-atom 
concentration in the electron-irradiated bulk sample than in the self-ion irradiated FIM sample.

The Stage II SIA recovery flux observed by FIM from 45 to $120 \mathrm{~K}$ is therefore an intrinsic phenomenon for the pure $W$ specimens. We feel that it is caused by the long-range migration and/or dissolution of SIA complexes formed during the long-range migration in Stage I ( $38 \mathrm{~K})$. Only when large quantities of specific impurity atoms $\left(5 \times 10^{-5}\right.$ at.fr. C, $5 \times 10^{-3}$ and $3 \times 10^{-2}$ at.fr. Re) were introduced into solid solution did the basic FIM recovery spectrum exhibit significant changes. At these impurity levels the SIA-impurity atom interactions began to dominate over SIA-SIA interactions. The small decrease of the amount of recovery for the $38 \mathrm{~K}$ peak in the $W(C)$ alloys, and the virtual elimination of Stages I and II in the $\mathrm{W}-3 \times 10^{-2}$ at.fr. $\mathrm{Re}$ alloys were indicative of the SIA capture cross-sections and dissociation enthalpies of the different SIA-impurity atom complexes.

In order to understand the experimental observations in a more quantitative fashion a diffusion model was constructed for the FIM Stage I isochronal recovery experiments. The following approximations were made in modeling the experiment: (1) the FIM tip was approximated by a sphere with a $300 \AA$ radius; (2) the depleted zone produced by a single incident-ion was taken to be a $15 \AA$ radius sphere whose center lay at the center of the spherical FIM tip; (3) the spherical depleted zone was surrounded by 100 SIAs at radii $(r)$ greater than or equal to $40 \AA ;(4)$ the SIA distribution function $[f(r)]$ was chosen arbitrarily to be proportional to $r^{-1}$ with a maximum SIA concentration of $2 \times 10^{-3}$ at.fr.; and (5) the impurity atoms were distributed uniformly between the outer and inner spherical surface. The coupled set of non- linear partial differential equations governing this situation were solved numerically; in order to obtain an isochronal recovery spectrum the specimen's temperature was increased in a linear fashion through Stage I. In this diffusion problem the SIAs were allowed to form immobile di-SIAs, immobile SIAimpurity atom complexes and to diffuse to either the outer or inner surface; the SIAs were not allowed to detrap below $50 \mathrm{~K}$. The effects, on the Stage I recovery behavior, of impurity-atom concentrations ranging from $10^{-6}$ to $10^{-1}$ at.fr. were determined. Further details concerning this model can be found in the appendix.

The results of these calculations are exhibited in Fig. 9. This figure shows, as a function of the impurity-atom concentration: (1) the fraction of SIAs that form di-SIAs; (2) the fraction of SIAs that become trapped at impurity atoms; and (3) the fraction of SIAs that escape to the outer surface ( $r=300 \AA$ ) during Stage I. The fraction of SIAs that arrive at the depleted zone surface is omitted from Fig. 9. The numerical values are, of course, sensitive to factors such as the SIA distribution function and tip geometry; nevertheless, the results indicate the qualitative trends in the competition between di-SIA formation and impurity-atom trapping. For low impurity-atom concentrations $\left(\sim 10^{-6}-10^{-5}\right.$ at.fr.) diSIA formation dominates the internal trapping possibilities. This impurity-atom regime includes the pure W specimen with $R=5 \times 10^{4}-15$. At $\sim 10^{-4}$ at.fr., di-SIA formation is still significantly greater than impurity atom trapping but the Stage I SIA flux to the surface is diminished as impurity atoms begin to trap mobile SIAs that would otherwise have reached the surface in the absence of impurity atoms. Therefore, as seen in the C-doped samples, Stage I decreases

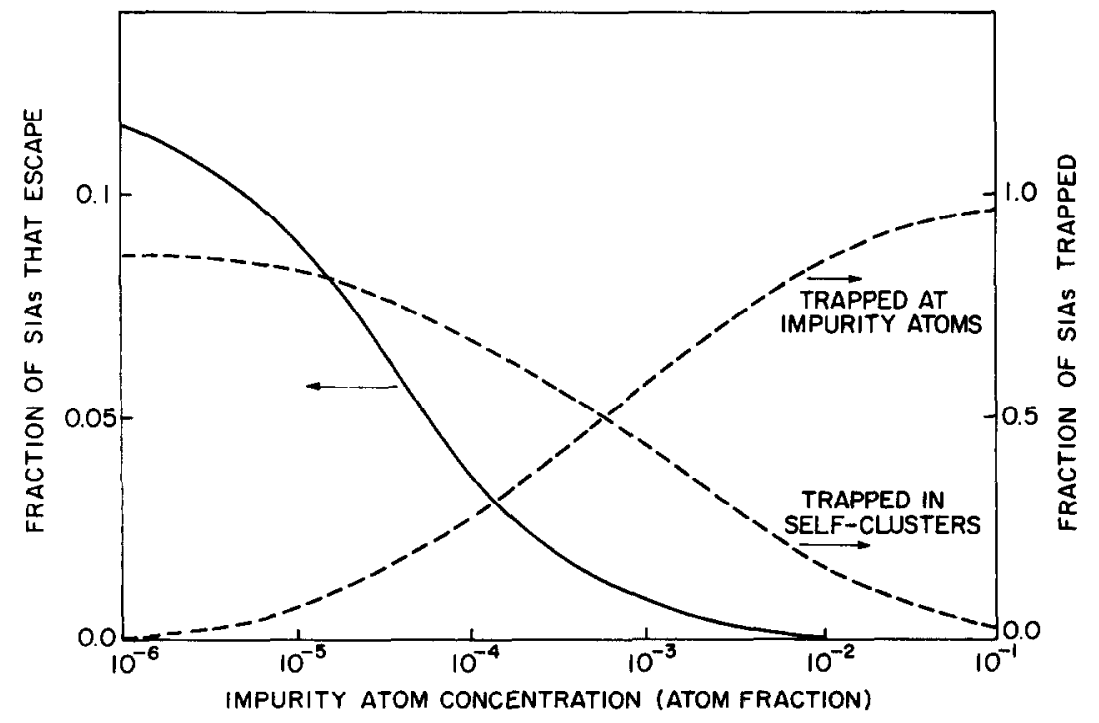

Fig. 9. A plot of the fraction of SIAs that were trapped during Stage I and the fraction of SIAs that had escaped to the outer surface during Stage I as a function of the impurity-atom concentration. These results were obtained by solving the set of coupled non-linear partial differential equations that governed the situation; see appendix for further details. 
slightly in magnitude but Stage II (45-12 K) is essentially unchanged because almost all of the trapped SIAs still reside in di-SIA clusters. Finally, for impurity-atom concentrations approaching $\sim 10^{-2}$ at.fr., impurity-atom trapping became the dominant reaction. Virtually no SIAs reached the outer surface during Stage I, and in Stage II the SIA flux to the surface was controlled totally by SIA-impurity atom binding enthalpies. In the experiment with $3 \times 10^{-2}$ at.fr. Re alloys, no significant recovery was observed below $120 \mathrm{~K}$. The results of the diffusion model are therefore in good qualitative agreement with the FIM observations of SIA recovery in pure and alloyed $W$.

In conclusion, the early Stage II SIA recovery spectrum observed by the FIM technique, for self-ion irradiated $W$ has been shown to be intrinsic in nature, and has been attributed to the dissolution and/or migration of SIA complexes formed during the Stage I long-range SIA migration. SIA-impurity atom effects were shown to play a dominant role in the early Stage II recovery spectrum only at very high impurity-atom concentrations of the impurity rhenium. The importance of SIA-SIA interactions can be traced to the highly anisotropic spatial-distribution of SIAs in a $30 \mathrm{keV} \mathrm{W}^{+}$irradiated FIM specimen.

Acknowledgements-The authors wish to thank Mr. B. F. Addis for his help in the preparation of the zone-refined single crystals of $\mathrm{W}$ and the $\mathrm{C}$-doped $\mathrm{W}$ specimens, $\mathrm{Mr}$. C. H. Nielsen for measuring the resistivity ratios of the W(Re) alloys, Mrs. K. Pratt for her aid in scanning ciné film and Mr. R. Whitmarsh for his general technical assistance.

\section{REFERENCES}

1. F. W. Young, Jr., J. nucl. Mater. 69 and 70, 310 (1978).

2. T. H. Blewitt, R. R. Coltman, C. E. Klabunde and T. S. Noggle, J. appl. Phys. 28, 639 (1957).

3. D. G. Martin, Phil. Mag. 6. 839 (1961); D. G. Martin, ibid. 7,803 (1962).

4. A. Sosin, in Lattice Defects and Their Interactions (edited by R. R. Hasiguti), pp. 235-266. Gordon and Breach. New York (1967).

5. C. P. Cannon and A. Sosin, Rad. Effects 25, 253 (1975).

6. W. Schilling, K. Sonnenberg and H. J. Dibbert, Rad. Effects 16, 57 (1972).

7. H. Wollenberger, in Proc. Fundamental Aspects of Radiation Damage in Metals (edited by M. T. Robinson and F. W. Young, Jr.), pp. 582-600. National Technical Information Service, Springfield, Springfield, Virginia (1975).

8. H. Wollenberger, J. nucl. Mater. 69 and 70, 361 (1978).

9. C. Dimitrov, in Proc. Fundamental Aspects of Radiation Damage in Metals (edited by $\mathrm{M}$. T. Robinson and F. W. Young, Jr.), pp. 608-14. National Technical Information Service, Springfield, Virginia (1975).

10. M. L. Swanson, L. M. Howe and A. F. Quennville, ibid. pp. $316-24$.

11. M. L. Swanson and F. Maury, Can. J. Phys. 53, 1117 (1975); M. L. Swanson, L. M. Howe and A. F. Quenncville, J. nucl. Mater. 69 and 70,372 (1978).

12. M. Kiritani, in Proc. Fundamental Aspects of Radiation Damage in Metals (edited by $M$. T. Robinson and F. W. Young, Jr.), pp. 695-714. National Technical Information Service, Springfield, Virginia (1975).
13. K. Nakata, K. Ikeuchi, H. Hirano, K. Furukawa and J. Takamura, ibid. pp. 622-28.

14. W. Mansel, G. Vogl and W. Koch, Phys. Rev. Lett. 31 359 (1973).

15. G. Vogl, J. Phys. 35, C6-165 (1974)

16. G. Vogl, in Proc. Fundamental Aspects of Radiation Damage in Metals (edited by $M$. T. Robinson and F. W. Young, Jr.). pp. 349-60. National Technical Information Service, Springfield, Virginia (1975).

17. C.Y. Wei and D. N. Seidman, Rad Effects 32, 221 (1977).

18. H. Wagenblast and A. C. Damask, $J$. Phys. Chem. Solids 32, 221 (1962).

19. M. Wuttig, J. T. Stanley and H. K. Stanley and H. K Birnbaum. Phys. Stat. Sol. 27, 701 (1968).

20. M. Weller and J. Diehl, Scripta metall. 10, 101 (1976).

21. K. Niebel and M. Wilkens, Phys. Stat. Sol. (a) 25, 77 (1974).

22. G. Burger, K. Isebeck, R. Kerter, J. Vökl, H. Wenzl, H.-H. Kuhlmann and H. Schultz, Phys. Lett. 20, 470. $472(1966)$.

23. A. Bourret, Phys Stat. Sol. (a) 4, 813 (1971)

24. K. Urban and A. Seeger, Phil. Mag. 30, 1395 (1974).

25. P. Ehrhart and W. Schilling, Phys. Rev. B 8, 2604 (1973).

26. P. Ehrhart and U. Schlagheck, J. Phys. F: Metal Phys. 4, 1575 (1974); P. Ehrhart and U. Schlagheck, ibid. 4, 1589 (1974)

27. H. B. Afman, Phys. Stat. Sol. (a) 11, 705 (1972); H. B. Afman, in Proc. International Meeting on Defects in Refractory Metals (edited by R. deBatist. J. Nihoul and L. Staals), pp. 19-20. Studie Centrum voor Kernenergie/Centre d'Etude Nucleaire, Mol, Belgium (1972)

28. P. Moser, ibid. pp. 65-7.

29. M. W. Thompson, Phil Mag. 5, 278 (1960).

30. R. R. Coltman, C. E. Klabunde and J. K. Redman, Phys. Rev. 156, 715 (1967).

31. S. Takamura, R. Hanada, S. Okuda and H. Kimura, $J$. phys. Soc. Japan 30, 1091 (1971).

32. H. H. Neely, D. W. Keefer and A. Sosin, Phys. Stat Sol. 28, 675 (1968).

33. W. Kunz, Phys. Stat. Sol. (b) 48, 387 (1971).

34. W. Kunz, K. Faber, R. Lachenmann and H. Schultz, in Proc. the International Meeting on Defects in Refractory Metals tedited by $\mathrm{R}$. deBatist, $J$. Nihoul and $\mathrm{L}$. Staals), pp. 7-12. Studie Centrum voor Kernenergie/ Centre d'Etude de L'Energie Nucleaire, Mol, Belgium (1972).

35. F. Dausinger and H. Schultz, Phys. Rev. Lett. 35, 1773 (1975); F. Uausinger, Phil. Mag. A37, 819 (1978).

36. F. Maury, M. Biget, P. Vajda, A. Lucasson and P. Lucasson, Rad. Effects 38, 53 (1978).

37. J. A. DiCarlo, C. L. Snead, Jr. and A. N. Goland, Phys. Rev. 178, 1059 (1969)

38. S. Okuda and H. Mizubayashi, Phys. Rev. Lett. 34, 815 (1975).

39. S. Okuda and H. Mizubayashi, Phis. Rex, B 13, 4207 (1976).

40. J. R. Townsend, M. Schildcrout and C. Reft, Phus. Rev. $B$ 14, $500(1976)$.

41. For reviews of the FIM technique and some of its applications see: (a) Field-Ion Microscopy (edited by J. J. Hren and S. Ranganathan). Plenum Press, New York (1968); (b) E. W. Müller and T.-T. Tsong. FieldIon Microscopy. American Elsevier, New York (1969); (c) K. M. Bowkett and D. A. Smith, Field-Ion Microscopy. North-Holland, Amsterdam (1970); (d) E. W Müller and T.-T. Tsong, in Progress in Surface Science (edited by S. G. Davison). Vol. 4. Part 1, pp. 1-139 Pergamon Press, Oxford (1973): and (e) J. A. Panitz, in Progress in Surface Science (edited by S. G. Davison) Vol. 8, pp. 219-262. Pergamon Press, Oxford (1978).

42. D. N. Seidman, in Radiation Damage in Metals (edited 
by N. L. Peterson and S. D. Harkness), pp. $28-57$ American Society for Metals, Metals Park, Ohio (1976).

43. D. N. Seidman, J. Phys. F: Metal Phys. 3, 393 (1973).

44. D. N. Seidman, K. L. Wilson and C. H. Nielsen, in Proc. Fundamental Aspects of Radiation Damage in Metals (edited by M. T. Robinson and F. W. Young, Jr), pp. 373-96. National Technical Information Service, Springfield, Viginia (1975).

45. R. M. Scanlan, D. L. Styris and D. N. Seidman, Phit. Mag. 23, 1439 (1971).

46. R. M. Scanlan, D. L. Styris and D. N. Seidman, Phil. Mag. 13, 1459 (1971).

47. K. L. Wilson and D. N. Seidman, Rad. Effects 27, 67 (1975)

48. D. N. Seidman, K. L. Wilson and C. H. Nielsen, Phys. Rev. Lett. 35, 1041 (1975).

49. V. Y. Startsev, N. V. Volkenshteyn and G. A. Nikitina, Fiz. Metal. Metalloved. 26, 261 (1968).

50. F. Dausinger, H. Schultz, K. Bönig and G. Vogl, Tagungstortrag, Physikertagung in Freudenstadt, April (1974); F. Dausinger and H. Schultz, Phys. Rev. Lett. 35, $1773(1975)$.

51. M. Hansen and K. Anderko, Constitution of Binary Alloys, p. 392. McGraw-Hill (1958); E. Fromm and H. Jehn, Metall. Trans. 3, 1685 (1972).

52. E. Krautz, H.-H. Kuhlmann and H. Schultz, $Z$. Metallk. 59, 133 (1968)

53. A. Shepella, Ph.D. Thesis, Cornell University (1970)

54. A. Sosin and H. Neely, Phys. Rev. 127, 1465 (1962).

55. W. Schilling, G. Burger, $K$. Isebeck and $H$. Wenzel, in Vacancies and Interstitials in Metals (edited by $\mathrm{A}$. Seeger, D. Schumacher, W. Schilling and J. Diehl), pp. 255-361. North-Holland, Amsterdam (1970).

56. C. H. Nielsen, M.S. Thesis, Cornell University (1977).

57. C. H. Nielsen and D. N. Seidman, to be published.

58. D. N. Seidman and K. H. Lie, Acta metall. 20, 1045 (1972).

59. T. J. Wilkes, J. M. Titchmarch, G. D. W. Smith, D. A. Smith, R. F. Morris, S. Johnston, T. J. Godfrey and P. Birdseye, J. Phys. D: Appl. Phys. 5, 2226 (1972).

60. B. Loberg, Phil. Mag. 24, 593 (1971).

61. L. A. Beavan, R. M. Scanlan and D. N. Seidman, Acta metall. 19, 1339 (1971).

62. C.-Y. Wei, Ph.D. Thesis, Cornell University (1978); C.-Y. Wei and D. N. Seidman, Appl. phys. Lett. 34, 622 (1979).

63. M. Drechsler and P. Wolf, in Proc. 4th Int. Cong. Electron Microscopy, Vol. I, p. 835. Springer-Verlag, Germany (1958).

64. W. Schilling, P. Ehrhart and K. Sonnenberg, in Proc. Fundamental Aspects of Radiation Damage in Metals (edited by M. T. Robinson and F. W. Young, Jr.), pp. 470-492. National Technical Information Service, Springfield, Virginia (1975).

65. R. A. Johnson, Phys. Rev. 134, A1329 (1964)

66. C. W. Gear, Numerical Initial Value Problems in Ordinary Differential Equations. Prentice-Hall, Englewood Cliffs, N.J. (1971).

\section{APPENDIX}

In this Appendix we give some details concerning the diffusion model discussed in Section 4. The inner and outer radii of the solid annular spherical volume are denoted $r=a$ and $r=b$, respectively. All SIA clusters of a size greater than a di-SIA were neglected and it was assumed that the impurity-atom traps were unsaturable. Subject to all the assumptions and approximations stated, the set of coupled non-linear partial differential equations is

+ The entropy change of migration $\left(\Delta s_{1 i}^{m}\right)$ of an SIA has been taken to be equal to zero.

$$
\begin{gathered}
\frac{\partial C_{1 i}}{\partial t}=D_{1 i}\left[\frac{\partial^{2} C_{1 i}}{\partial r^{2}}+\frac{2}{r} \frac{\partial C_{1 i}}{\partial r}\right]-2 K_{1} C_{1 i}^{2}-K_{2} C_{*} C_{1 i} \\
\frac{\partial C_{2 i}}{\partial t}=K_{1} C_{1 i}^{2}
\end{gathered}
$$

and

$$
\frac{\partial C_{* i}}{\partial t}=K_{2} C_{*} C_{1 i}
$$

The rate constants $K_{1}$ and $K_{2}$ and the SIA diffusion coefficient $\left(D_{1 i}\right)$ are given by the expressions

$$
\begin{aligned}
& K_{1}=g_{1} v_{1 i} \exp \left(-\Delta h_{1 i}^{m} / k T\right), \\
& K_{2}=g_{2} v_{1 i} \exp \left(-\Delta h_{1 i}^{m} / k T\right),
\end{aligned}
$$

and

$$
D_{1 i}=g_{3} a_{0}^{2} v_{1 i} \exp \left(-\Delta h_{1 i}^{m} / k T\right) .
$$

The quantities $C_{1 i}, C_{2 i}, C_{* i}$, and $C_{*}$ are the concentrations of SIAs, di-SIA, SIA-impurity atom complexes, and impurity atoms, respectively. The quantity $\Delta h_{\mathrm{i}}^{m}$ in the enthalpy change of migration of the SIA, $\uparrow v_{1 i}$ is the frequency with which an SIA attacks the enthalpy barrier, $g_{1}, g_{2}$, and $g_{3}$ are geometric factors, and $a_{0}$ is the lattice parameter. The equations (A1) to (A3) were subjected to the initial conditions $(t=0)$

$$
\begin{aligned}
& C_{1 i}=f(r), \\
& C_{2 i}=0,
\end{aligned}
$$

and

$$
C_{*_{i}}=0
$$

The boundary conditions were taken to be

$$
C_{1 i}(r)=0, \text { at } r=a,
$$

and

$$
C_{1}(r)=0 \text {, at } r=b \text {. }
$$

The expression for $D_{1 i}$ was taken from the work of Scanlan et al. $[45,46]$

$$
D_{1 i}=0.22 \exp (-0.085 \mathrm{eV} / k T) \mathrm{cm}^{2} \mathrm{~s}^{-1} \text {. }
$$

The quantity $g_{1}$ is the number of ways a di-SIA can be formed from two single SIAs, $g_{2}$ is the number of ways an SIA-impurity atom cluster can form and $g_{3}$ is a diffusional factor which depends on the crystal lattice. The SIA was assumed to have the $\langle 110\rangle$ split configuration in the b.c.c. tungsten lattice [64]. The di-SIA was assumed to consist of two parallel $\langle 110\rangle$ split SIAs with their center-of-gravity located on two first nearest-neighbor sites [65]. With these assumptions we calculated $g_{1}, g_{2}$ and $g_{3}$ to be 66,10 , and $(1 / 6)$ respectively. The quantity $v_{1 i}$ was calculated from equations (A6) and (A9).

The SIAs were taken to be immobile initially at $18 \mathrm{~K}$. The temperature of the specimen was then increased linearly with time $(t)$ to the end of Stage I $(45 \mathrm{~K})$. The coupled set of nonlinear partial differential equations [equations (A1) to (A3)] were solved numerically by first approximating each partial differential equation by $N$ ordinary differential equations in time. A uniform set of 60 radial mesh points was used. The resulting system of 180 coupled ordinary differential equations was solved numerically using the Gear method [66]. The concentration profiles of the trapped SIAs were integrated over volume to yield the total number of SIAs trapped during Stage 1 . The flux of SIAs at the outer surface $-D_{1 i}\left(\partial C_{1 i} / \partial r\right)_{r=b}$ was integrated over time to yield the total number of SIAs that reached the outer surface during Stage I. These SIA totals are shown in Fig. 9 as a function of the impurity atomconcentration. 